\title{
ANÁLISE EVOLUTIVA dOS PROCESSOS EROSIVOS DA BACIA DO RIBEIRÃO ALAM GREI - SP ATRAVÉS DO MODELO DA EQUAÇÃO UNIVERSAL DE PERDAS DE SOLO
}

\author{
Patrícia BORGES \\ Cenira M. LUPINACCI ${ }^{2}$
}

\section{Resumo}

A problemática ambiental da erosão dos solos tem se intensificado nos dias atuais, sendo alvo de vários estudos e pesquisas que visam buscar soluções frente à problemática do esgotamento dos solos, principalmente àqueles submetidos às práticas agrícolas. A bacia hidrográfica do Alam Grei é uma destas áreas que vêm sofrendo com o desencadeamento dos processos erosivos em toda a sua extensão, na qual se constata que a alteração antrópica, principalmente com a retirada da mata original para o uso de pastagens, plantação de cana-de-açúcar e áreas construídas, vem acarretando a formação de feições geomorfológicas que indicam tais processos em seus vários estágios de evolução. Tal área constitui-se ainda em setor de expansão urbana do sítio de Rio Claro. Desta forma, esse artigo tem por objetivo apresentar dados que possibilitam avaliar historicamente o comportamento dos processos erosivos na bacia do Ribeirão Alam Grei, por meio da Equação Universal de Perdas de Solo, considerando o uso da terra nos anos de 1972, 1995 e 2008. Assim, considera-se que será possível oferecer informações que contribuam para o planejamento ambiental da bacia a fim de que as ações nessa desenvolvidas venham a ser compatíveis com a capacidade de suporte do meio físico da área.

Palavras-chave: Bacia Hidrográfica. Erosão dos Solos. Práticas Agrícolas.

\section{Abstract \\ Historical evaluation of the behavior of the erosive process in Alam Grei's hydrographic basin - SP using the Universal Soil Loss Equation}

Nowadays the environmental problem of soil erosion has gotten bigger and has been a target of several studies and researches that aim to look for solutions to the problem of the soil exhaustion, mainly those ones submitted to agricultural practice. Alam Grei's hydrographic basin is one of these areas that are suffering with erosive processes in all its extension where it is possible to verify that the anthropic alteration, mainly because of the removal of the original forest for pasture, sugarcane plantation and built areas, has been causing the formation of geomorphologic features which indicate such processes in their several evolution stages. So, the proposed research aims to historically evaluate the behavior of the erosive processes in the basin of Alam Grei streamlet through the Universal Soil Loss Equation in 1972, 1995 and 2008, seeking to offer information to contribute to the environmental planning of the basin so that the actions developed there come to be compatible with the support capacity of the area physical environment.

Key words: Hydrographic Basin. Soil Erosion. Agricultural Practice.

\footnotetext{
${ }^{1}$ Mestre em Geografia (Organização do Espaço) pelo Programa de Pós- Graduação em Geografia da UNESP - Campus de Rio Claro. E-mail: patygeo@gmail.com

2 Profa. Dra. do Departamento de Planejamento Territorial e Geoprocessamento (Deplan/IGCE/ UNESP - Campus de Rio Claro) e coordenadora do Laboratório de Geomorfologia (LAGEO). E-mail: cenira@rc.unesp.br
} 


\section{INTRODUÇÃO}

A degradação ambiental no mundo contemporâneo tem acarretado sérios problemas para a humanidade que sofre as consequências de um sistema natural alterado pela ação antrópica. Christofoletti (1979, p. 55) ao se referir ao equilíbrio do sistema natural afirma que a natureza, sendo um sistema, tem seu equilíbrio dependente do "[...] ajustamento completo das suas variáveis internas às condições externas". Quando influências externas modificam partes do sistema, o todo é também alterado, pois suas partes estão estreitamente inter-relacionadas. Solo, relevo, clima e vegetação são partes integrantes dos sistemas naturais e qualquer alteração em uma dessas partes vai repercutir nas demais, rompendo o equilíbrio dinâmico existente.

Dentre os elementos dos sistemas naturais, os solos têm merecido especial atenção, especialmente nos últimos anos, em razão de sua intensa exploração, sobretudo para as atividades agrícolas. Tal exploração tem provocado um grande e complexo problema ambiental, devido aos vários fatores que o envolvem, a saber, a erosão.

Tal problema ambiental, a erosão dos solos, tem afetado em grande proporção toda a extensão territorial da bacia do ribeirão Alam Grei, no Município de Rio Claro SP. Essa bacia hidrográfica sofre com as alterações antrópicas, principalmente com a retirada de suas matas para o uso de pastagens e cultivo de cana-de-açúcar, o quem vem acarretando a formação de feições geomorfológicas que indicam processos erosivos em seus vários estágios de evolução.

Desta forma, esse artigo tem por objetivo apresentar dados que possibilitam avaliar historicamente o comportamento dos processos erosivos na bacia do ribeirão Alam Grei por meio da Equação Universal de Perdas de Solo (EUPS), nos cenários de 1972, 1995 e 2008, a fim de oferecer subsídios ao planejamento territorial da área a fim de que as ações nela desenvolvidas não afetem a integridade do sistema natural.

\section{A EROSÃo dos SOLOS E A EQUAÇÃo UNIVERSAL DE PERDAS DE SOLO (EUPS)}

De acordo com Bertoni e Lombardi Neto (1990) a erosão é o processo de desprendimento e arraste acelerado das partículas do solo pela ação da água e do vento. Todavia, os mesmos autores afirmam que a luta do homem contra a erosão é tão antiga quanto a própria agricultura, luta esta que se iniciou quando o homem substituiu o nomadismo pelo sistema fixo de vida e assim houve a necessidade de intensificar o uso da terra, levando a destruição da cobertura de superfície e acarretando a exposição do solo às forças erosivas. Cunha (1997) afirma que, atualmente, não se pode excluir a ação antrópica da análise dos processos erosivos, já que este é o responsável pela dinamização de tais processos.

[ ] iniciada no momento em que o material é fragilizado propiciando a dinamização da força de cisalhamento ante a força de coesão, criando condições para que qualquer agente, incluindo-se aí o homem, auxiliado pelo estímulo da força de gravidade, promove o deslocamento deste material até o nível de base mais próximo. (CUNHA, 1997, p.54)

Constata-se, desta forma, que a problemática da erosão dos solos é complexa, dado aos vários fatores responsáveis pelo seu desenvolvimento. Todavia, nota-se 
nesse processo a ação de dois agentes no desencadeamento dos processos erosivos, sendo um físico e outro antrópico.

Entende-se assim que a erosão dos solos é um processo físico natural que está diretamente relacionado com as características do terreno, ou seja, da declividade e do comprimento de rampa, das chuvas, da densidade da cobertura vegetal e, como afirmam Bertoni e Lombardi Neto (1990, p 45), "da capacidade que tem o solo de absorver água e, por forças passivas, como a resistência que exerce o solo à ação erosiva da água".

Lepsch (2010, p. 184) com relação a importância da cobertura vegetal para proteção dos solos afirma que:

Em seu estado natural, a vegetação cobre o solo como um manto protetor; sua remoção é muito lenta na maior parte do planeta, e compensada pelos contínuos processos de formação. Desta forma, o desgaste erosivo é equilibrado pelos contínuos processos de renovação do solo [ ] (LEPSCH, 2010, p. 184)

Porém, a ação antrópica pode intensificar os processos erosivos, principalmente com a retirada da cobertura vegetal para o uso agrícola, já que os solos passam a ser desprotegidos, possibilitando a ação mais rápida e intensa dos fatores responsáveis pela erosão. De acordo com Lepsch (2010, p. 184) o solo que se encontra desprotegido de sua vegetação original poderá se debilitar ao estar exposto a vários fatores. A velocidade dessa degradação, segundo o autor citado, dependerá também das características do clima e da topografia do local.

Este fato se faz notável na área de estudo da presente pesquisa, a qual apresenta um uso da terra agropecuário intenso, o que vem gerando feições no relevo que denunciam a atuação de processos erosivos por toda sua extensão, como constatado in loco.

Diante do exposto, como afirma Salomão (2007, p. 229), várias abordagens têm sido utilizadas para o estudo dos processos erosivos. Em geral, a autora afirma que as abordagens distinguem-se entre as que procuram realizar a quantificação das perdas de solo por erosão e as que buscam a avaliação qualitativa do comportamento erosivo dos terrenos. Segundo Gameiro (2003), a utilização de modelos matemáticos para avaliar as perdas de solo de uma área cultivada vem se tornando uma prática de grande utilidade para o planejador conservacionista e para os estudos ambientais.

Neste contexto, a Equação Universal de Perdas do Solo (USLE - Universal Soil Loss Equation) ou EUPS, como é conhecida no Brasil, constitui-se em um dos modelos mais antigo e utilizado em diversas partes do globo para quantificar perdas de solo por erosão, surgida da compilação de modelos anteriores. A EUPS envolve dois conjuntos de fatores (naturais e antrópicos), que pelo processo multiplicativo entre estes, resulta numa perda anual de solos, por unidade de área (ton./ha./ano), sendo sua fórmula expressa da seguinte forma: $A=$ R.K.LS.C.P, onde: A. é a perda de solos; R. é a erosividade da chuva; K. é a erodibilidade do solo; LS. é o fator topográfico; C. é o uso e manejo da terra e P. são as práticas conservacionistas.

A aplicação do modelo EUPS na pesquisa relatada nesse artigo foi realizada em três períodos distintos, com a intenção de analisar como o dinamismo do uso e ocupação da terra ao longo de trinta e quatro anos se correlaciona com o desencadeamento dos processos erosivos na bacia. 


\section{A ÁREA DE ESTUDO}

A bacia hidrográfica do ribeirão Alam Grei, localizada no setor norte do município de Rio Claro - SP, próximo ao Distrito de Ajapi (Fig.1), apresenta formas de relevo que indicam a ocorrência de processos erosivos intensos, em seus vários estágios de desenvolvimento, como verificado in loco.

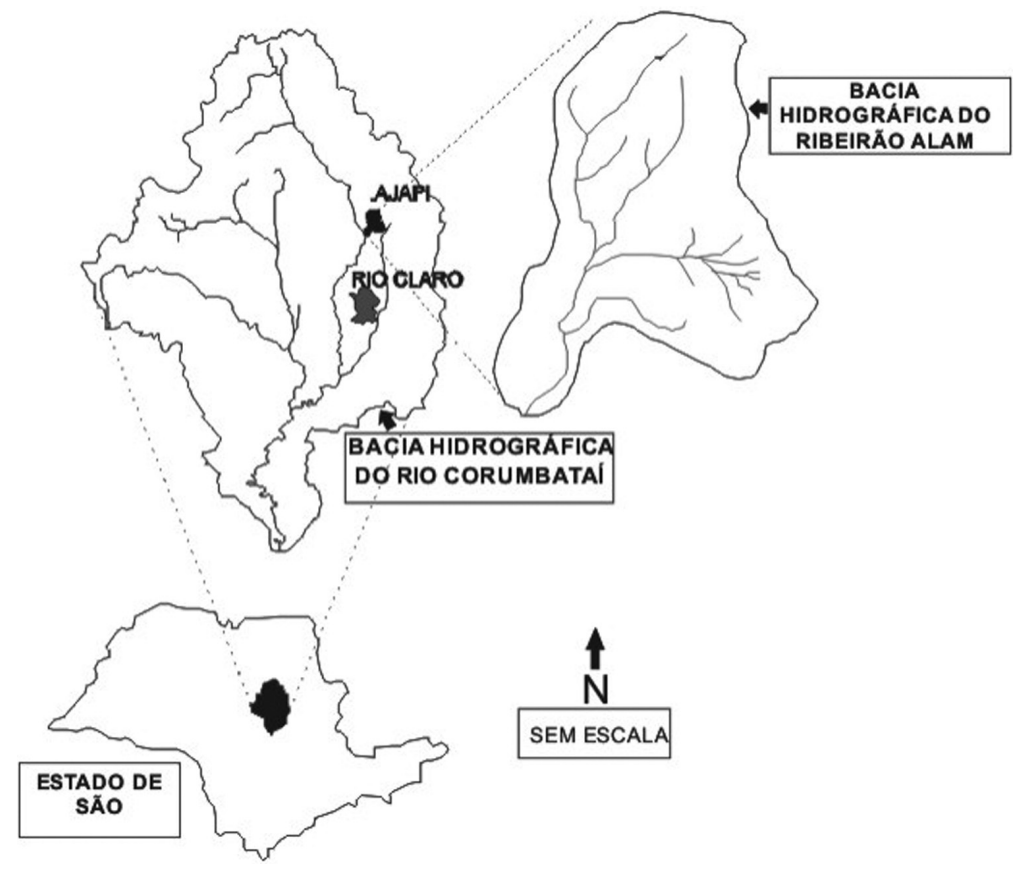

Figura 1 - Localização da Bacia do Ribeirão Alam Grei - SP

A referida bacia, de acordo com o atual Plano Diretor (2006), está localizada dentro do perímetro rural do município, e seu deságue encontra-se no limite deste perímetro. No total, a bacia apresenta uma área de $12 \mathrm{Km}^{2}$, e seu deságue ocorre na margem esquerda do Rio Corumbataí, do qual o ribeirão Alam Grei é afluente direto. A maior parte da bacia apresenta altas declividades do terreno, com fundos de vale bastante encaixados, o que denota uma possível retomada erosiva das drenagens. Além disso, ocorrem processos erosivos lineares os quais geram grande número de sulcos erosivos, ravinas e voçorocas.

\section{MÉTODO}

A fim de se alcançar os objetivos traçados a pesquisa, foi utilizada a abordagem direta e indireta da Bacia do Ribeirão Alam Grei. A primeira foi realizada por meio de trabalhos de campo e a segunda por revisão bibliográfica, cartográfica e de elaboração de documentos cartográficos da área. 
Como orientação metodológica, utilizou-se a Teoria Geral dos Sistemas aplicada à ciência geográfica. De acordo com Cunha (2001), a referida teoria tem sido amplamente empregada por profissionais dedicados à questão ambiental e seu emprego tem sido analisado como um dos mais produtivos no que se refere aos resultados obtidos.

De acordo com Thornes e Brunsden (citado por CHRISTOFOLETTI, 1979, p. 3) "o sistema funciona para executar uma determinada tarefa, procurando atingir um objetivo ou finalidade". A matéria, a energia e a estrutura são aspectos importantes que, segundo Christofoletti (1979), devem ser abordados no estudo da composição dos sistemas. "A matéria corresponde ao material que vai ser mobilizado através do sistema [...] A energia corresponde às forças que fazem o sistema funcionar, gerando a capacidade de realizar trabalho" (CHRISTOFOLETTI, 1979, p.8). Quanto à estrutura do sistema, Christofoletti (1979, p.13) coloca que esta "é constituída pelos elementos e suas relações, expressando-se através do arranjo de seus componentes. O elemento é a unidade básica do sistema".

\section{TÉCNICAS}

Para melhor compreensão, as técnicas da pesquisa serão descritas em duas etapas distintas. A primeira se refere as técnicas cartográficas, cujas cartas construídas apresentaram dados intermediários para posteriores cálculos dos fatores da EUPS. Os fatores que contemplam a EUPS constituem a segunda etapa das técnicas de pesquisa.

\section{AS TÉCNICAS CARTOGRÁFICAS}

\section{Carta de Formas de Vertente}

A carta de forma de vertentes foi elaborada visando individualizar os diferentes segmentos destas que apresentam morfologias diversificadas. Este documento foi elaborado a partir da interpretação da configuração das curvas de nível existentes na Base Cartográfica, construída a partir da Carta Topográfica de Rio Claro Folha Granja Ipê - SF.23-Y-A-I-4-NE-D, escala 1:10.000, CESP, editada em 1978. Além dessa base, utilizou-se ainda o acompanhamento por fotografias aéreas e trabalho de campo. Desta forma, separaram-se os setores côncavos, convexos e retilíneos da área pesquisada, para se obter o comprimento das rampas existentes na presente bacia. Os limites entre as formas de vertente constituem-se no primeiro critério de organização das parcelas de cálculo para a aplicação da Equação Universal de Perdas de Solo.

\section{Cartas de Uso e Ocupação da Terra}

As cartas de Uso e Ocupação da Terra foram elaboradas por meio da fotointerpretação de pares estereoscópicos de fotografias aéreas, na escala aproximada de 1:25.000, do ano de 2006, obtidas com a Base Aerofotogrametria e Projetos AS; 1:5.000, do ano de 1995, obtidas junto ao SEPLADEMA, e na escala aproximada 
de $1: 25.000$, do ano de 1972 , obtidas junto ao DEPLAN, sendo a primeira reambulada posteriormente em campo para a atualização dos dados. Durante este processo, foram identificadas e mapeadas também as práticas conservacionistas existentes na área de estudo. Os dados qualitativos mapeados nas Cartas de Uso e Ocupação da Terra foram, posteriormente, transformados em informações quantitativas que constituíram o fator CP para a aplicação da EUPS, que será apresentado posteriormente.

\section{Carta de Declividade}

A técnica de construção da carta de declividade da bacia hidrográfica do Ribeirão Alam Grei seguiu a proposta desenvolvida por De Biasi (1970).

\section{Dados de Solos}

Os dados pedológicos constituem-se de fundamental importância para a realização da presente pesquisa. Assim, a elaboração do documento cartográfico referente aos tipos de solos se deu em duas etapas. Inicialmente, os dados de solos foram compilados de documentos cartográficos disponíveis na bibliografia, sendo estes: IAC - Carta Pedológica Semi-Detalhada, Folha São Carlos - SF.23-Y-A-I, escala 1:100.00, 1989; Koffler et al. Carta de Solos da Bacia do Rio Corumbataí - UNESP/ IGCE/ Departamento de Cartografia e Análise da Informação Geográfica - Campus Rio Claro, 1992, escala 1:50.000. Todavia, por se tratarem de escalas muito pequenas, estes dados foram reambulados em campo, a fim de que houvesse maior precisão das classes de tipos de solo, bem como das áreas de transição entre estas classes. Assim, os limites dos tipos de solos foram traçados com maior precisão, alterando-se a carta original. Posteriormente, os dados de solo foram transformados em dados quantitativos, para o cálculo do fator erodibilidade (K) da EUPS.

\section{Base de Cálculos dos Fatores da EUPS}

A base de cálculos para a aplicação dos fatores da EUPS foi elaborada a fim de que, em cada parcela de cálculo, fossem agrupadas as mesmas características físicas e antrópicas. Primeiramente, foi construída a carta de formas de vertentes, na qual a base cartográfica da bacia do ribeirão Alam Grei foi dividida em setores retilíneos, côncavos e convexos, assim como, nesta carta, também foram identificados os setores de fundos de vale, que foram excluídos da divisão. Esta primeira divisão foi realizada a fim de viabilizar as medidas do comprimento de rampa. A carta de forma de vertentes foi, portanto, utilizada como primeira divisão da base cartográfica, a fim de construir a base de cálculos. Com base na carta de formas de vertentes, foram realizadas novas divisões das parcelas de cálculo, pela sobreposição desta com a carta dos tipos de solos da bacia do ribeirão Alam Grei, com a carta clinográfica e com as cartas de uso e ocupação da terra. 


\title{
TÉCNICAS DE OBTENÇÃO DOS FATORES DA EUPS
}

\author{
Fator Topográfico (LS)
}

Para se realizar o cálculo do fator topográfico utilizou-se a proposta de Bertoni e Lombardi Neto (1985), os quais sugerem a seguinte equação:

LS $=0,00984 . C^{0,63}, \mathbf{D}^{\mathbf{1}, 18}$, onde: LS = Fator Topográfico; C = Comprimento de rampa em metros e $D=$ Grau de declividade em \%.

O valor do grau de declive foi obtido com base na carta clinográfica, segundo proposta de Mendes (1993). Para isto, foi necessário estabelecer os valores médios de cada classe de declividade da bacia hidrográfica do Alam Grei. Além da obtenção dos valores médios de cada classe, foi necessário também estabelecer os valores médios do agrupamento de cada duas classes de declividade, já que para a aplicação da EUPS as parcelas de cálculo foram subdivididas por meio do agrupamento de classes de declividade próximas. As classes de declividade da bacia do ribeirão Alam Grei foram mapeadas na carta de declividade descrita anteriormente. Após calculada as médias da declividade, pela sobreposição da carta clinográfica com a da base de cálculos, foram obtidos os valores do fator $\mathrm{S}$ para cada parcela de análise da bacia.

Já o comprimento de rampa foi obtido por meio de medidas efetuadas a partir dos divisores d'água até os fundos de vale. Várias medidas foram realizadas dentro de cada parcela definida pela forma de vertente, buscando-se a maior e a menor medida de distância entre a cumeada e os fundos de vale. Após serem feitas essas medidas, foi calculada a média do comprimento de rampa para cada parcela. De posse de tais dados, aplicou-se a fórmula acima apresentada.

\section{Erosividade $(R)$}

Para a obtenção dos dados de erosividade da chuva, foi utilizada a equação proposta porLombardi Neto e Moldenhauer (1980): $\mathbf{E I}=\mathbf{6 7}, 355$ ( $\left.\mathbf{R}^{\mathbf{2}} \mathbf{/ \mathbf { p }}\right) \mathbf{0 . 8 5}$, onde:

$\mathrm{El}=$ média mensal do índice de erosão (MJ.mm/h./L); $\mathrm{R}=$ precipitação média mensal em milímetros; $p=$ precipitação média anual em milímetros.

Os valores da erosividade da chuva $(R)$ foram obtidos pela soma dos valores mensais do índice de erosão (EI). Os dados pluviométricos necessários à aplicação da fórmula foram obtidos junto ao posto pluviométrico instalado na Fazenda São José, posto este localizado na bacia hidrográfica do córrego Cachoeirinha, bacia vizinha à do ribeirão Alam Grei. Este posto foi escolhido pela proximidade com a área de estudo, o que torna os seus dados mais precisos. A partir destes dados calculou-se a média mensal e anual de precipitação, por meio das quais foi possível obter os dados de El mensais, cuja soma constitui-se no valor de erosividade da chuva (R) utilizado para a bacia.

\section{Erodibilidade dos Solos (K)}

$\mathrm{Na}$ presente pesquisa, os valores de $\mathrm{K}$ utilizados baseiam-se na pesquisa de Bueno (1994). Os dados foram escolhidos devido à compatibilidade das classes de tipos de solo pesquisados pela autora citada, com as que se encontram na bacia do ribeirão Alam Grei. A autora se baseou na proposta de Bertoni e Lombardi Neto (1990), com adaptações por comunicação pessoal com Lombardi Neto. 


\section{Uso e Manejo do Solo (C) e Práticas Conservacionistas (P)}

Os dados qualitativos de uso e manejo do solo, obtidos pela carta de uso da terra, foram transformados em dados quantitativos a partir dos valores apresentados por Stein et al. (1987), já que o autor faz um detalhamento minucioso para cada tipo de uso e manejo do solo, compatíveis com as que se encontram na bacia do ribeirão Alam Grei.

Quanto às práticas conservacionistas, Stein et al (1987) incorporam estes valores juntamente com os de $C$, já que os avaliam conjuntamente. Bertoni e Lombardi Neto (1985) apontam quatro tipos principais de práticas conservacionistas: plantio morro abaixo, plantio em contorno, alternância de capinas + plantio em contorno e cordões de vegetação permanentes. Estes são os mesmos considerados por Stein et al (1987).

\section{As Cartas Síntese}

Como produtos finais foram elaboradas as cartas de potencial natural (PNE) à erosão e de estimativa de perdas de solo (EPS) por erosão dos anos de 2008, 1995 e 1972. A primeira corresponde aos valores adquiridos para cada unidade de análise sem a intervenção humana. Nesta são utilizados os valores de erosividade da chuva, erodibilidade do solo e do fator topográfico. Quanto à segunda, além de contemplar os fatores naturais, apresenta também o fator uso e manejo do solo e as práticas conservacionistas. As três cartas foram construídas após obtidos os valores de todos os fatores da EUPS já descritos, sendo estes transcritos para uma planilha de cálculo processada no Programa Excel, cujos fragmentos podem ser observados nas tabelas a seguir:

Tabela 1 - Fragmento da Planilha de Cálculo do PNE elaborada para a bacia do ribeirão Alam Grei - SP

\begin{tabular}{|c|c|c|c|c|c|c|}
\hline Parcela: & $\begin{array}{c}\text { L* } \\
\text { (rampa) }\end{array}$ & $\begin{array}{c}\text { S* } \\
\text { (declive) }\end{array}$ & LS* & K* & R* & PNE* \\
\hline 1 & 45 & 1 & 0,108273 & 0 & 7153,418 & 0 \\
\hline 2 & 60 & 13 & 2,677217 & 0,033 & 7153,418 & 631,9913 \\
\hline 3 & 70 & 4,5 & 0,843719 & 0,034 & 7153,418 & 205,206 \\
\hline 4 & 60 & 13 & 0,765634 & 0,034 & 7153,418 & 186,2146 \\
\hline 5 & 55 & 1 & 2,534409 & 0,033 & 7153,418 & 598,2797 \\
\hline 6 & 50 & 1 & 0,115703 & 0,034 & 7153,418 & 28,14095 \\
\hline 7 & 45 & 9 & 0,108273 & 0,034 & 7153,418 & 26,33368 \\
\hline 8 & 30 & 13 & 1,120954 & 0,033 & 7153,418 & 264,6154 \\
\hline 9 & 45 & 13 & 2,233429 & 0,033 & 7153,418 & 527,2295 \\
\hline 10 & 55 & 13 & 2,534409 & 0,034 & 7153,418 & 616,4094 \\
\hline
\end{tabular}




\section{Tabela 2 - Fragmento da Planilha de Cálculo da EPS do ano de 2008}

\begin{tabular}{|c|c|c|c|c|c|c|c|c|}
\hline Parcela: & $\begin{array}{c}\text { L* } \\
\text { (rampa) }\end{array}$ & $\begin{array}{c}\text { S* } \\
\text { (declive) }\end{array}$ & LS* & K* & R* & PNE* & CP* & EPS2008* \\
\hline 1 & 45 & 1 & 0,108273 & 0 & 7153,418 & 0 & 0,01 & 0 \\
\hline 2 & 60 & 13 & 2,677217 & 0,033 & 7153,418 & 631,9913 & 0,05 & 31,59956 \\
\hline 3 & 70 & 4,5 & 0,843719 & 0,034 & 7153,418 & 205,206 & 0,05 & 10,2603 \\
\hline 4 & 60 & 4,5 & 0,765634 & 0,034 & 7153,418 & 186,2146 & 0,05 & 9,310728 \\
\hline 5 & 55 & 13 & 2,534409 & 0,033 & 7153,418 & 598,2797 & 0,05 & 29,91399 \\
\hline 6 & 50 & 1 & 0,115703 & 0,034 & 7153,418 & 28,14095 & 0,01 & 0,281409 \\
\hline 6,1 & 50 & 1 & 0,115703 & 0,034 & 7153,418 & 28,14095 & 0,00004 & 0,001126 \\
\hline 7 & 45 & 1 & 0,108273 & 0,034 & 7153,418 & 26,33368 & 0,01 & 0,263337 \\
\hline 8 & 30 & 9 & 1,120954 & 0,033 & 7153,418 & 264,6154 & 0,01 & 2,646154 \\
\hline 8,1 & 30 & 9 & 1,120954 & 0,033 & 7153,418 & 264,6154 & 0,05 & 13,23077 \\
\hline 9 & 45 & 13 & 2,233429 & 0,033 & 7153,418 & 527,2295 & 0,05 & 26,36147 \\
\hline 10 & 55 & 13 & 2,534409 & 0,034 & 7153,418 & 616,4094 & 0,05 & 30,82047 \\
\hline 10,1 & 55 & 13 & 2,534409 & 0,034 & 7153,418 & 616,4094 & 0,00004 & 0,024656 \\
\hline
\end{tabular}

Cabe ressaltar que para cada ano analisado foi construída uma nova tabela de cálculo da EPS. Os valores numéricos do potencial natural à erosão foram classificados qualitativamente por se tratarem de uma simulação da EUPS, já que concerne a uma abstração da realidade na qual se considera que o terreno está totalmente desprovido de cobertura. Quanto aos valores das classes de estimativa de perda de solo, estes foram estabelecidos após realizados os cálculos de EPS dos três cenários estudados, a fim de possibilitar análise comparativa dos períodos. A classificação ocorreu por análise dos gráficos de frequência desses dados. As classes estabelecidas foram: $<0,05$ ton/ha/ano; 0,05 \& 1 ton/ha/ano; 1 - 2,5 ton/ha/ano; 2,5 5 ton/ha/ano; 5 ト 10 ton/ha/ano; $\geq 10$ ton/ha/ano.

\section{ANÁLISE DOS RESULTADOS}

A Carta de Potencial Natural à Erosão, PNE, (Fig. 2) demonstrou que uma das áreas que apresenta um grande potencial natural à erosão é a área do setor leste da bacia onde hoje se encontra o bairro do Alam Grei. Esta apresenta classes com valores altos de PNE, que variam entre médio e muito forte nas médias e baixas vertentes, fato este relacionado às altas declividades, que variam de $12 \%$ a $30 \%$. Além disso, estas áreas localizadas nas médias e baixas vertentes são cobertas por Neossolos Litólicos e Argissolos, que, no cálculo da EUPS, apresentam os mais altos valores de erodibilidade entre os tipos de solo da bacia do ribeirão Alam Grei.

No ano de 1972, o bairro rural do Alam Grei ainda não existia, e essas áreas possuíam uso para pasto e pasto sujo. Assim, a classe predominante de Perdas de Solo (Fig. 3) desta área era de 2,5 a 5 ton/ha/ano nas médias e baixas vertentes. Já nas altas vertentes, nas quais a classe de PNE é Muito Fraca, a classe de perdas de solo é de 0,5 a 1ton/ha/ano. Nos anos de 1995 e 2008 (Fig. 4 e 5), o bairro rural do Alam Grei já estava bastante desenvolvido e, assim, essas áreas não foram consideradas no cálculo de perdas de solo pela EUPS. 


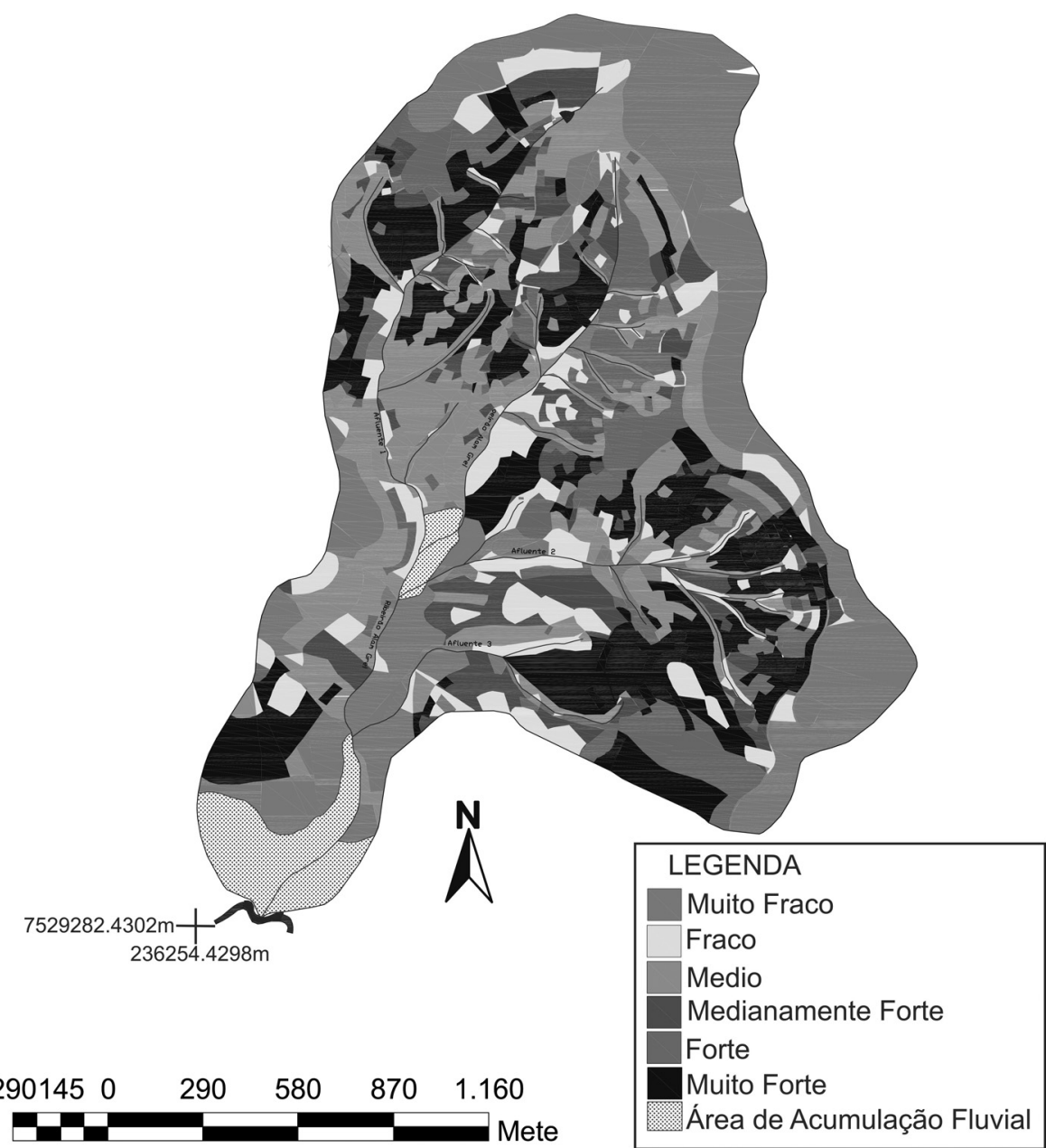

Fonte: Carta Topográfica de Rio Claro Folha - Granja Ipê - SF. 23-Y-A-I-4-NE-D, escala 1:10.000, CESP, 1978; Borges, P. Carta de Formas de Vertentes da Bacia do ribeirão Alam Grei; Borges, P. Carta Clinográfica da Bacia do ribeirão Alam Grei; Borges, P. Carta de Tipos de Solos da Bacia do ribeirão Alam Grei. Elaboração: Borges, P.

Orientação: Cunha, C.L.
Convenções Cartográficas

$Y$ Rede de Drenagem

Limite da bacia

Figura 2 - Carta de Potencial Natural à Erosão da Bacia do Ribeirão Alam Grei - SP 
Outro setor da bacia que apresenta valores bastante altos de Potencial Natural à Erosão são as áreas de nascentes do afluente 2. Esta área possui vertentes com declividades muito acentuadas, onde predominam as classes entre $12 \%$ a maior ou igual a $30 \%$ que, associadas aos Neossolos Litólicos, fazem com que esta área possua, predominantemente, a classe de PNE Muito Forte. Assim, estas áreas também possuíam altos valores de perdas de solo no ano de 1972, já que o uso da terra, sobressalente, era o pasto sujo, que possui um valor alto no cálculo de perdas de solo na EUPS. Em 1972, a classe predominante de perdas neste setor era de 5 a 10 ton/ha/ ano. No ano de 1995, estas áreas continuam tendo altos valores de perdas de solo, já que o uso predominante continua sendo o pasto e o pasto sujo. Porém, já é possível notar as matas ciliares margeando os cursos da água, o que faz com que nas baixas vertentes a classe de perdas seja menor. Assim, neste ano constata-se que as classes variam bastante de 2,5 a 10 ton/ha/ano, nas médias vertentes e menor que 0,05 ton/ ha/ano, nos locais ocupados pela vegetação das matas ciliares. No ano de 2008 , 0 cenário não se modificou muito em relação ao de 1995 . As áreas de pasto são predominantes, porém as áreas de mata também aumentaram, o que faz com que os valores de perdas continuem variando bastante nas médias vertentes, como no ano de 1995, mas apresentam valores bem menores nos locais ocupados pelas matas, menor que 0,05 ton/ha/ano.

A classe de PNE Muito Forte é predominante também nos interflúvios entre as nascentes do afluente 3. Este fato ocorre em virtude desta área apresentar alto valor do fator topográfico no cálculo de perdas de solo da EUPS. Apesar da sua declividade não ser tão acentuada quanto à do setor analisado anteriormente, variando de $6 \%$ a $20 \%$, estas vertentes possuem um extenso comprimento, o que se reflete diretamente no fator topográfico. Consequentemente, seu potencial erosivo é de classe Muito Forte, já que está aliado aos solos do tipo Neossolos Litólicos, que predominam nesta área. Em 1972, estas áreas eram ocupadas pelo uso de pasto e pasto sujo, fazendo com que a classe dos valores de perdas de solo fosse também alta, predominando a maior que 10 ton/ha/ano.

Em 1995, os valores de perdas não mudaram muito neste setor, já que o uso da terra era destinado ao cultivo da cana-de-açúcar, fazendo com que estes setores também apresentassem valores de perdas maiores que 10 ton/ha/ano. Porém, nas baixas vertentes, onde já se registravam matas ciliares em extensões significativas, esta classe de perda cai muito e chega a menor que 0,05 ton/ha/ano. É importante ressaltar que, no ano de 1995 toda a área ocupada pelo cultivo da cana-de-açúcar nas áreas de cabeceiras e margens direita e esquerda do afluente 3 possuía altas classes de perdas de solo que variavam de 5 a 10ton/ha/ano e maior que 10 ton/ha/ ano. Este fato se deve ao significado quantitativo alto do cultivo da cana-de-açúcar na Equação de Perdas de Solo, mesmo com práticas conservacionistas. No ano de 2008, o cenário neste setor continuava muito parecido com o de 1972 e 1995, onde o uso da terra predominante eram os pastos e pastos sujos. Porém, constata-se uma vegetação de mata ainda maior do que em 1995, margeando os cursos de água. Este fato faz com que a classe de perdas predominante seja maior que 10 ton/ha/ano, tornando-se menor apenas nas áreas ocupadas pelas matas, onde a classe é de menor que 0,05 ton/ha/ano. 


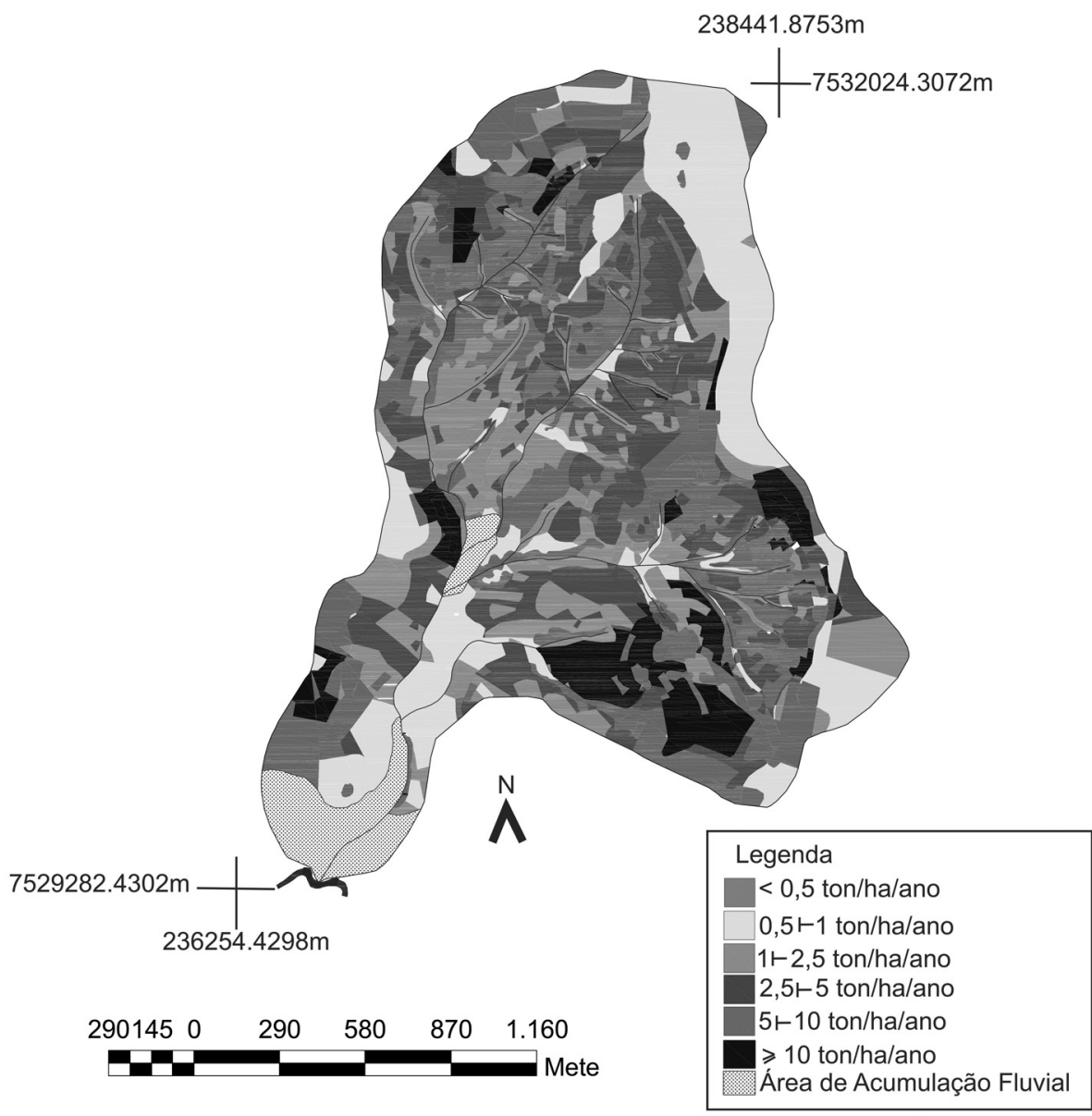

Fonte: DEPLAN, Fotografias Aéreas da Bacia do ribeirão Alam Grei, 1972; Borges, P. Carta de Uso e Ocupação da Terra da Bacia do ribeirão Alam Grei, 1972; Borges, P. Carta de Potencial Natural à Erosão da Bacia do ribeirão Alam Grei.

Elaboração: Borges, P.

Orientação: Cunha, C.L.

Convenções Cartográficas

Rede de Drenagem Limite da Bacia

Figura 3 - Carta de Estimativa de Perdas de Solo da Bacia do Ribeirão Alam Grei - SP - 1972 e 1995 


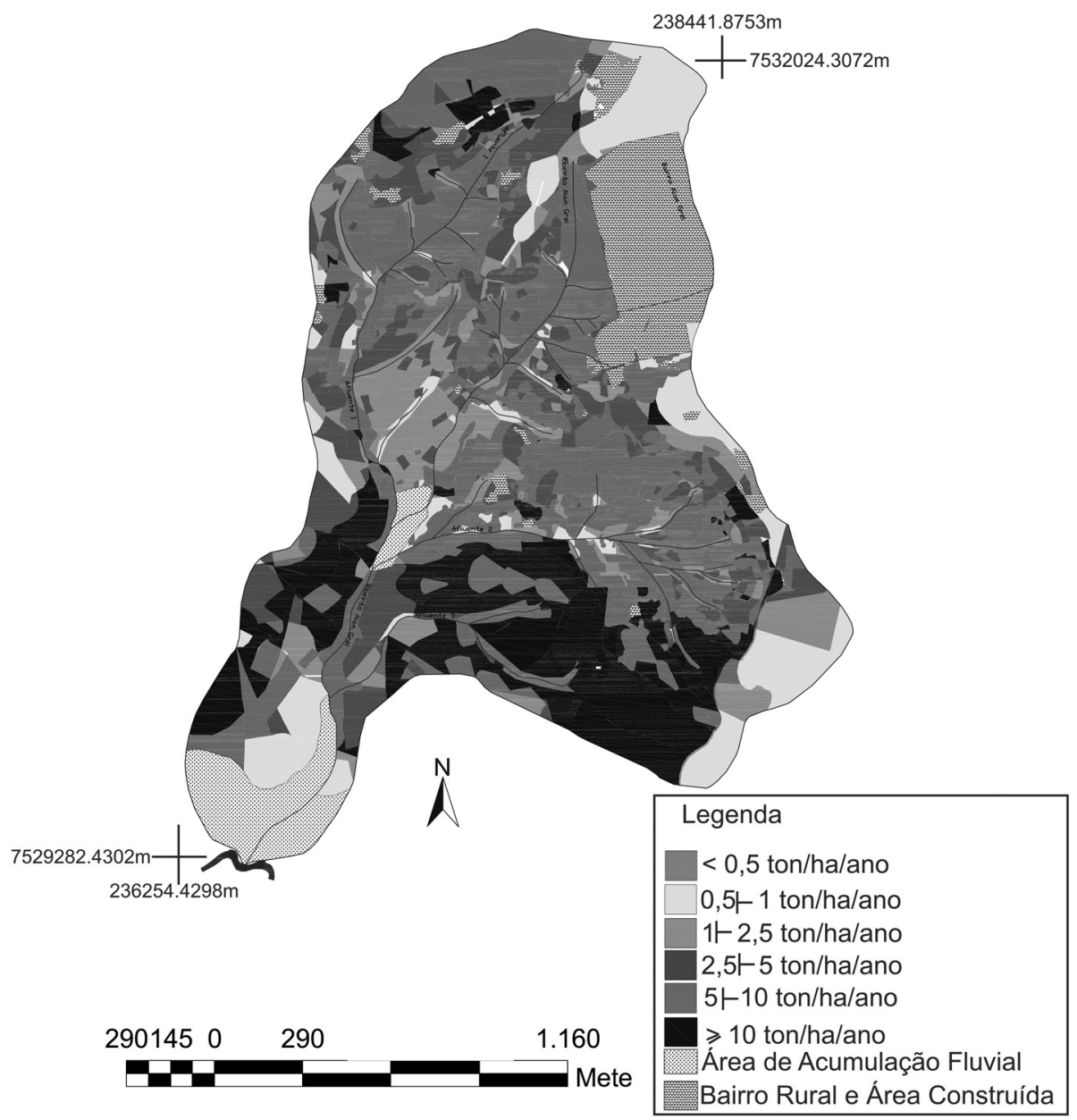

Fonte: DEPLAN, Fotografias Aéreas da Bacia do ribeirão Alam Grei, 1995; Borges, P. Carta de Uso e Ocupação da Terra da Bacia do ribeirão Alam Grei, 1995; Borges, P. Carta de Potencial Natural à Erosão da Bacia do ribeirão Alam Grei.

Elaboração: Borges, P.

Orientação: Cunha, C.L.

Convenções Cartográficas

$Y$ Rede de Drenagem Limite da Bacia

Figuras 4 - Carta de Estimativa de Perdas de Solo da Bacia do Ribeirão Alam Grei - SP - 1972 e 1995 


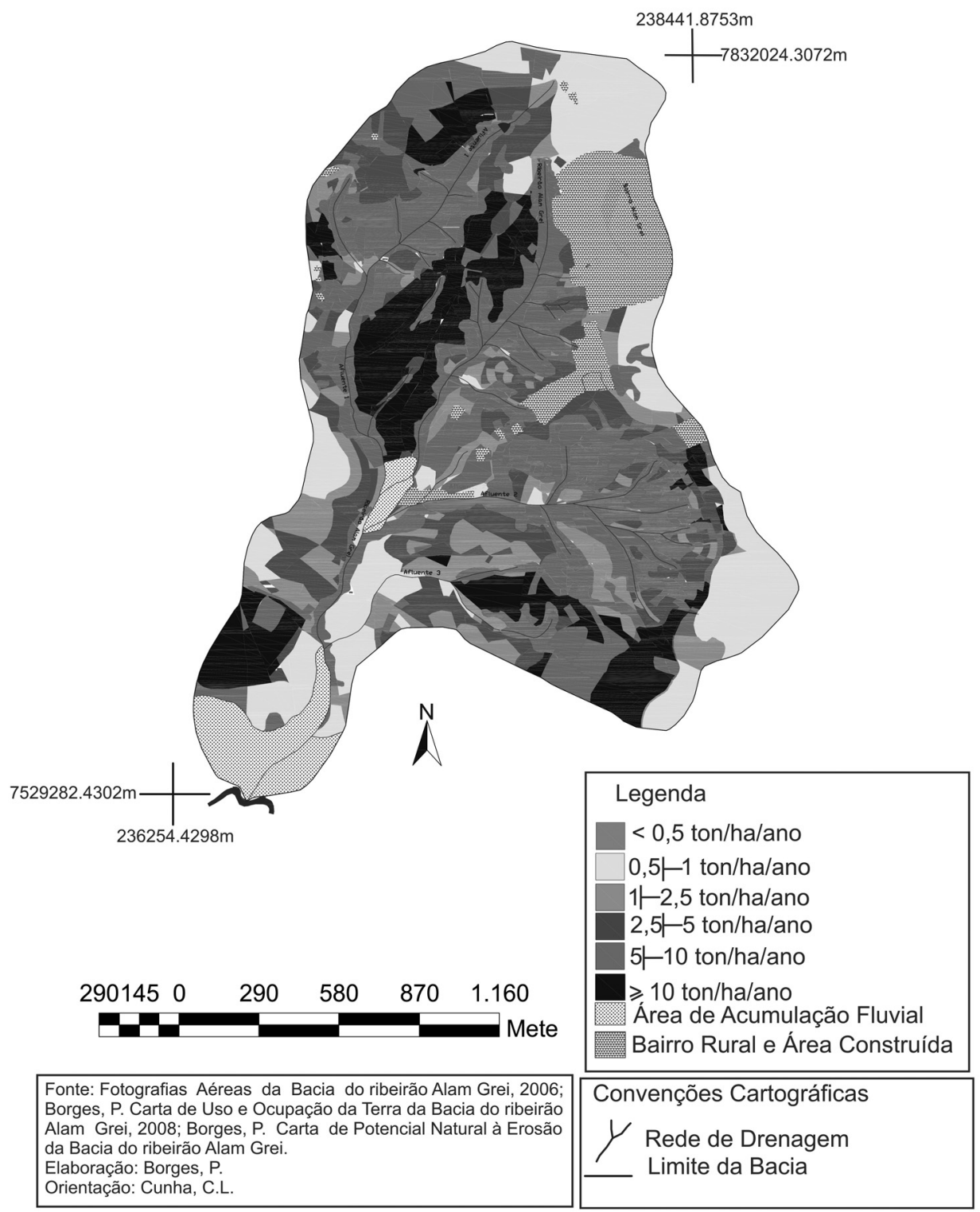

Figura 5 - Carta de Estimativa de Perdas de Solo da Bacia do Ribeirão Alam Grei - SP - 2008 
Na margem esquerda do afluente 1 , no setor do seu alto curso, também podese verificar o predomínio das classes Forte e Muito Forte de Potencial Natural à Erosão. Estas áreas possuem classes de declividade muito altas, que variam entre 20 a $30 \%$. Além disso, há a presença dos Neossolos Litólicos e dos Argissolos, o que torna estas áreas com valores de PNE, predominantemente, Forte e Muito Forte. Algumas destas áreas possuem declividades menores, com classes entre $6 \%$ a $20 \%$. Porém, as extensões das vertentes são grandes, o que faz com que o fator topográfico possua um valor alto no cálculo das perdas de solo pela EUPS. Consequentemente, estas áreas possuem classes de PNE Forte. Este fato faz com que no ano de 1972, os valores de perdas neste setor variassem entre 2,5 a 10 ton/ha/ano, sendo menores apenas nos locais onde as matas constituíam a cobertura vegetal dos solos. Todavia, neste ano, o uso predominante na área eram os pastos. Já em 1995, as classes de perda de solo posicionam-se entre 2,5 a 5 ton/ha/ano, seguido da classe 5 a 10 ton/ ha/ano. Este fato se deve ao uso ser mais variado, possuindo áreas de pasto, cultivo de cana-de-açúcar e cultura perene. Essas classes de perdas só diminuem nas baixas vertentes, ocupadas pelas matas ciliares. Já no ano de 2008, o uso oscilou bastante neste setor, que agora possui áreas de cultura anual, pasto, pasto sujo e uma extensão bem maior das matas. Nos locais onde predominam estas últimas, a classe de perdas de solo é a menor, 0,05 ton/ha/ano. Nas áreas de pasto e pasto sujo variam de 2,5 a 10ton/ha/ano. Já nas áreas de cultura anual esta classe se torna mais alta, maior que 10 ton/ha/ano, já que os valores de perdas das culturas anuais são os maiores na EUPS.

De maneira geral, verifica-se que, as classes mais baixas de PNE, da bacia do ribeirão Alam Grei, se concentram ao norte e extremo leste da bacia, nas áreas próximas ao limite da bacia. Este fato ocorre em razão da baixa declividade destes setores. Além disso, estas áreas apresentam uma associação de Latossolos, os quais apresentam o menor valor de erodibilidade na bacia do ribeirão Alam Grei, fatos estes que tornam estas áreas com valores de PNE Muito Fraco e Fraco. Assim, os valores de perdas de solo também são menores nestes locais, porém variam de acordo com o uso e ocupação da terra que cada local apresenta.

Cabe ressaltar que as áreas de fundo de vale, onde se encontram os Gleissolos, possuem valor de erodibilidade zero no cálculo de perdas de solo da Equação Universal de Perdas de Solo. Por este motivo, essas áreas de acumulação fluvial não foram avaliadas em termos de perdas e aparecem sem valores associados nas cartas de PNE e EPS dos períodos analisados.

De acordo com o gráfico 1 constata-se que, no geral, a bacia do ribeirão Alam Grei apresentou uma relativa melhora quanto às perdas de solo nos anos de 1995 e 2008, quando comparada ao ano de 1972, visto que as classes de menor perda de solo obtiveram uma maior representação territorial e as classes de maior perda tiveram uma queda significativa, com exceção da classe de maior que 10 ton/ha/ano, que aumentou.

Contudo, existem áreas que merecem um cuidado especial quanto ao uso e manejo da terra por possuírem classes altas de potencial à erosão. É possível constatar que a maioria das parcelas possui valores de PNE acima de 200 ton/ha/ano, chegando a valores próximos de 1.300 ton/ha/ano. É certo ressaltar que esses dados quantitativos foram transformados em classes qualitativas, já que não existem áreas desprovidas de uso e ocupação da terra. 


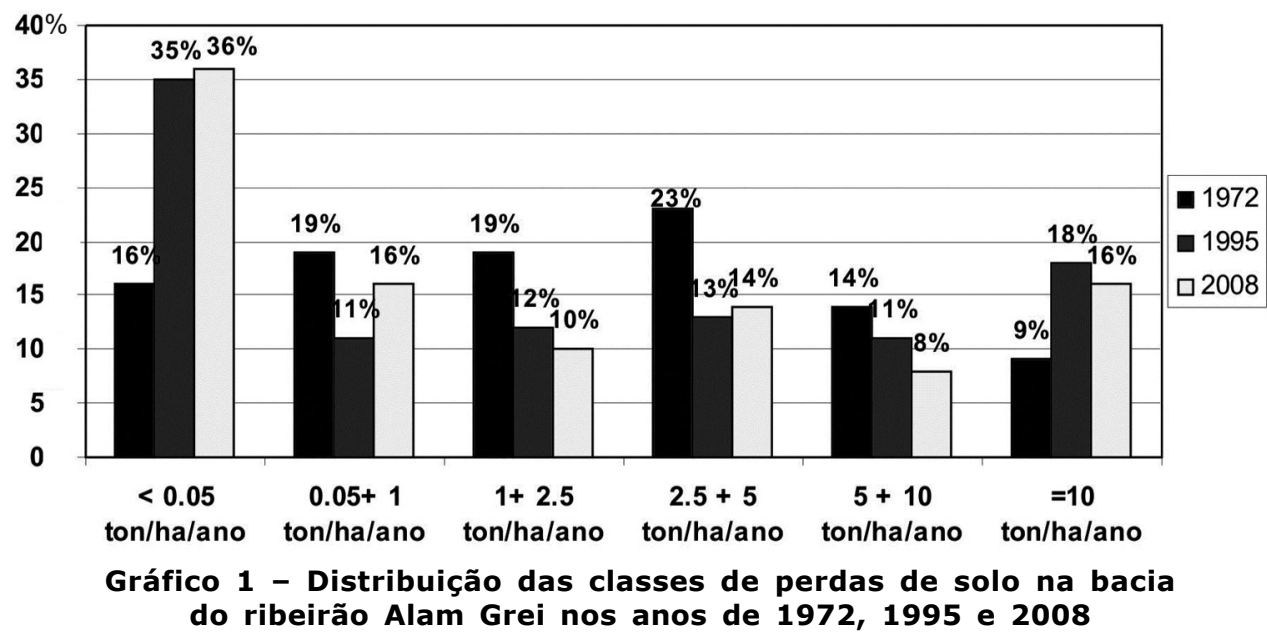

As áreas de declividade das vertentes entre 20 a $30 \%$, aliadas a solos com altos valores de erodibilidade, devem possuir tipos de cobertura vegetal que neutralizem ou diminuam a força da ação dos agentes erosivos no solo. Contudo, como visto nas Cartas de Uso e Ocupação da Terra, estas áreas nem sempre apresentam tais restrições. Isto se reflete nos valores de perdas de solos de cada cenário analisado, onde os valores de uso e ocupação da terra foram contabilizados juntamente com os dados do Potencial Natural à Erosão.

\section{CONSIDERAÇÕES FINAIS}

O uso da terra pode ocasionar grandes impactos ambientais quando esse não é compatível com a capacidade de suporte do meio. Tal fato pode ser verificado em toda extensão territorial da bacia do ribeirão Alam Grei, onde ora os valores de perdas de solo eram elevados, fruto de um uso e ocupação com altos valores de CP associados aos fatores naturais de grande potencial erosivo, ora os valores de perdas de solo eram baixos, pois dentre outros, apresentava uso e ocupação da terra adequados as características físicas do terreno.

É fato que a atividade agrícola é indispensável para a sobrevivência do homem na Terra, já que a mesma lhe fornece os alimentos e os combustíveis necessários para a manutenção da vida. Porém, como afirma Lepsch (2010, p. 183) essa atividade deve ser feita de forma sustentável, ou seja, com o menor impacto ambiental possível. Para o autor o homem vem cultivando a terra sem a consciência de que a mesma é um recurso esgotável e que, tal fato, trará consequência na distribuição de alimentos à humanidade, na medida que essa não para de crescer em números. Segundo ele:

Em muitos casos até parece que o homem se empenha em acelerar o empobrecimento das terras; as matas são derrubadas e queimadas desordenadamente; as encostas íngremes são aradas na direção da maior declividade; os pastos 
superlotados de rebanhos, e as terras cultivadas são submetidas a monocultura, ano após ano, sem proteção contra as enxurradas. (LEPSCH, 2010, p. 190)

Desta forma, na bacia do ribeirão Alam Grei, alguns fatos em relação ao uso e ocupação da terra merecem destaque como as áreas de cultivo da cana de açúcar que no ano de 1995 tiveram um aumento territorial significativo, ocupando quase toda a baixa bacia. Isto se refletiu nos valores de Perdas de Solo deste ano os quais alcançaram as classes mais altas, de 5 a 10 ton/ha/ano e maior que 10 ton/ha/ano. Este fato se deve ao alto valor do fator uso e manejo do solo que a cana-de-açúcar representa, mesmo utilizando práticas conservacionistas. Já no ano de 2008 , os valores de perdas de solo diminuem nesta área devido a regressão da área ocupada pelo cultivo da cana-de-açúcar, que cedeu espaço às áreas de pastagens. Desta forma, a classe de perda de solo predominante passou a ser de 1 a 2,5 ton/ha/ano.

A Carta de Potencial Natural à Erosão demonstrou que a bacia do ribeirão Alam Grei apresenta áreas bastante susceptíveis ao desencadeamento dos processos erosivos, o que indica que estas devam possuir coberturas vegetais capazes de amenizar os agentes desencadeadores de tais processos, como foi constatado pelas Cartas de Estimativa de Perdas de Solo, nas quais as áreas que obtiveram um crescimento considerável de sua vegetação original, com a presença de matas, registraram valores de perdas de solo menores que em outros tipos de uso analisados.

É importante ressaltar que, em 1972, estas áreas de mata eram quase inexistentes, sendo que sua regeneração foi constatada a partir dos cenários de 1995 e 2008, onde, sobretudo as matas ciliares obtiveram um crescimento em extensão territorial por toda a bacia. Desta forma, a presente pesquisa constatou que na bacia do ribeirão Alam Grei, a situação foi contrária a comumente registrada no cenário de degradação das matas ciliares, ocorrendo um aumento desta vegetação no decorrer dos anos, promovendo para estas áreas o registro de menores valores de perdas de solo para os anos de 1995 e 2008, do que no ano de 1972.

Todavia, é fato que, apesar das melhoras, a bacia ainda apresenta problemas sérios de erosão, já que possui áreas nas quais a suscetibilidade a tais processos é alta, como visto nos locais onde há o crescimento do bairro do Alam Grei, sendo necessário um maior controle dessas áreas de expansão residencial, e também um melhor manejo das terras para que o uso se torne mais compatível com a capacidade natural da bacia.

Dessa forma, as práticas conservacionistas se mostram indispensáveis para a proteção do solo fazendo com que a erosão diminua em proporções significativas. Para Lepsch (2010, p. 197):

As práticas conservacionistas evitam o impacto da água da chuva e depois o seu escoamento. Ao evitar as enxurradas, toda essa água infiltra-se no solo, sem remover o horizonte A, enriquecendo os mananciais subterrâneos. (LEPSCH, 2010, p. 197)

Nestes termos, a presente pesquisa veio a contribuir como instrumento de subsídio ao planejamento territorial da área, visto que espacializa as áreas mais susceptíveis ao desencadeamento dos processos erosivos, assim como os usos e ocupação da terra que mais favorecem esses processos por meio da análise e comparação dos dados de perdas de solo dos cenários de 1972, 1995 e 2008. Ainda, considera-se que a Equação Universal de Perdas de Solo foi um instrumento de valor na identificação da evolução dos processos erosivos, fornecendo dados úteis para o planejamento ambiental da bacia. Deve-se registrar que a natureza é mais complexa do que os 
modelos, porém os modelos são de extrema importância para o entendimento do sistema natural, e devem ser permanentemente aperfeiçoados.

\section{REFERÊNCIAS}

Atlas Ambiental da Bacia do Rio Corumbataí. Disponível em http:// www.ceapla.rc.unesp.br/atlas.html. Acesso em 05/2007.

BASE AEROFOTOGRAMETRIA E PROJETOS AS, Fotografias Aéreas da bacia do ribeirão Alam Grei, escala 1:25.000, 2006.

BERTONI, J.; LOMBARDI NETO, F. Manual Técnico de Manejo e Conservação do Solo e Água. Campinas: CATI, 1993.

BERTONI, J.; LOMBARDi NETO, F. Conservação do Solo. Ed. Livroceres, 2a edição. Piracicaba, 1985.

BERTONI, J.; LOMBARDI NETO, F. Conservação do Solo. Ed. Ícone, 3a Edição, São Paulo, 1990.

BUENO, C.R. Zoneamento da Sucetibilidade à Erosão dos Solos da Alta e Média Bacia do Rio Jacaré Pepira, SP, com Vistas ao Planejamento Ambiental. 1994. Tese (Doutorado em Geografia), Instituto de Geociências e Ciências Exatas UNESP - Rio Claro, 1994.

CESP. Carta Topográfica de Rio Claro. Folha - Granja Ipê - SF.23-Y-A-I-4-NE-D, escala 1:10.000.

CERON, A.O.; DINIZ, J.A.F. O Uso de Fotografias Aéreas na Identificação das Formas de Utilização Agrícola da Terra. Revista Brasileira de Geografia. Rio de Janeiro, n.2, p. 161-172, 1996.

CHRISTOFOleTti, A. Geomorfologia. São Paulo: Ed. Edgard Blucher, São Paulo, 1974.

CUNHA, C.M.L. Quantificação e Mapeamento das Perdas de Solo por Erosão com Base na Malha Fundiária. Dissertação (Mestrado em Geografia) - Instituto de Geociências e Ciências Exatas, UNESP, Rio Claro, 1997.

CUNHA, C.M.L. A Cartografia do Relevo no Contexto da Gestão Ambiental. 2001. 128f. Tese (Doutorado em Geociências e Meio Ambiente) - Instituto de Geociências e Ciências Exatas, UNESP, Rio Claro, 2001.

DE PLOEY, J.; GABRIELS, D.. Measuring soil loss and experimental studies. In: M.J. Kirkby; R.P.C. Morgan (Ed.). Soil Erosion. p. 63-108, 1980.

DE BIASI, M. Cartas de Declividade: Confecção e Utilização. Geomorfologia, São Paulo, n.21, p. 8-12, 1970.

DEPLAN, Fotografias Aéreas da Bacia hidrográfica do ribeirão Alam Grei, escala $1: 30.000,1972$.

DONZELI, P.L. et al. Técnicas de Sensoriamento remoto aplicadas ao Diagnóstico básico para Planejamento e Monitoramento de Microbacias Hidrográficas. Documentos IAC, Campinas, Instituto Agronômico, n. 29, p. 91 - 119, 1992.

KOFFLER, N.F. Solos da Bacia do Rio Corumbataí. Rio Claro: Universidade Estadual Paulista - IGCE - Departamento de Cartografia e Análise da Informação Geográfica. Escala 1:50.000, 1992. 
IAC, instuto agronômico de CAMPINAS. Carta Pedológica Semi-Detalha do Estado de São Paulo: Folha de São Carlos (SF.23-Y-A-IV), escala 1:100.000, 1989. IAC, INSTITUTO AGRONÔMICO DE CAMPINAS. Levantamento Pedológico Semidetalhado do Estado de São Paulo: Quadrícula São Carlos II. Memorial Descritivo. Campinas, 1984.

LEPSCH, I.F. Formação e Conservação dos Solos. São Paulo: Oficina de Textos, 2010.

LOMBARDI NETO, F. Rainfall erosivity - its distribution and relationship with soil loss as Campinas, Brasil. West Lafayette: Purdue University, 1977.

LOMBARDI NETO, F. Equação Universal de Perdas de Solo Modificada. Campinas: Seção de Conservação do Solo - IAC, 1994.

LOMBARDI NETO, F.; MOLDENHAUER. Erosividade da Chuva - sua distribuição e relação com perdas de solo em Campinas, SP. In: ENCONTRO NACIONAL DE PESQUISA DE CONSERVAÇÃO DO SOLO, 30, 1980, Recife. Anais. Recife: UFRPE, 1981, p.158.

MENDES, I. A. A Dinâmica Erosiva do Escoamento Pluvial na Bacia do Córrego Lafon - Araçatuba-SP. 1993. 156f. Tese (Doutorado em Geografia)- FFLCH, USP, São Paulo, 1993.

MINISTÉRIO DA AGRICULTURA-DIVISÃO DE GEOLOGIA E MINERALOGIA. Carta Geológica do Brasil: Quadrícula de São Carlos, escala 1:100.000, 1952.

OLIVEIRA, J.B; JACOMINE, P.K.T.;CAMARGO, M.N. Classes Gerais de Solos do Brasil- Guia auxiliar para seu reconhecimento. Jaboticabal: FUNEP, 1992.

Plano Diretor do Município de Rio Claro. Disponível em: http://HYPERLINK "http:/ /www.rioclaro.sp.gov.br"www.rioclaro.sp.gov.br. Acesso em 05/2007.

PROCHNOW, D. et al. Razão de perdas de terra e fator $C$ da cultura do cafeeiro em cinco espaçamentos, em Pindorama (SP). Revista Brasileira de Ciência de Solo. Viçosa, v. 29, n. 1, p. 91-98, 2005.

STEIN, D.P.,et al. Potencial de Erosão Laminar, Natural e Antrópico, na Bacia do Peixe - Paranapanema. In: SIMPÓSIO NACIONAL DE CONTROLE DE EROSÃO, 4, 1987, Marília, Anais. São Paulo: S.C.P., 1987.

TAVARES, A.C.; VITTE, A.C. Erosão do Solo e Assoreamento: O caso de Monte Aprazível - SP. Geografia. Rio Claro, v.18 , n.1, p.51-95, 1993.

WISCHMEIER, W.H. A Rainfall Erosion Index for a Universal Soil Loss Equation. Soil Science Society of America Proceedings. Madison, no 3, 1959.

WISCHMEIER, W.H.; SMITH, D.D. Predicting Rainfall Erosion Losses - A Guide to Conservation Planning. Washington, USDA Handbook, n. 537 (supplement), p. $1-58,1978$.

WISCHMEIER, W.H.; SMITH, D.D. Predicting Rainfall Erosion Losses from Cropland East of the Rocky Mountains. Washington, USDA Handbook , n. 537, p. 1-58, 1978.

Recebido em fevereiro de 2013 Revisado em outubro de 2015 Aceito em outubro de 2016 